\title{
Child Abuse in the Dental Setting
}

\author{
Caroline Blakley and Ryan D Brown* \\ Department of Pediatrics, University of Oklahoma College of Medicine, Oklahoma, USA
}

Submission: September 27, 2019; Published: October 11, 2019

*Corresponding author: Ryan D Brown, Department of Pediatrics, University of Oklahoma College of Medicine, Oklahoma, USA

\section{Introduction}

When someone thinks about child abuse, they normally do not think of the dental office or dentist as the place or person for which it is assessed. However, no one is immune to the effects of child maltreatment. The following article is meant to shed some light on the broad spectrum of child maltreatment: the epidemiology, the types, the presentations, and how to report.

\section{The Problem}

In order to talk about abuse, we must first define it. The Child Abuse Prevention and Treatment Act (CAPTA) by the federal government defines child maltreatment as, at a minimum: "Any recent act or failure to act on the part of a parent or caretaker which results in death, serious physical or emotional harm, sexual abuse or exploitation; or an act or failure to act, which presents an imminent risk of serious harm" [1]. In 2017, there were over 4.1 million calls to child protection services in the United States. These reports encompassed over 7.5 million children. Of these referrals 2.4 million cases were screened-in by Child Protective Services (CPS) agencies, which is a 12.2\% increase from 2013. After investigation, it was determined that $17 \%$ of the children were victims of abuse [2].

\section{Types of Abuse}

Child maltreatment is not just about the numbers. To understand the numbers, one must take a look at what comprises the numbers. Nationally, three-fourths (74.9\%) of victims were neglected, 18.3 percent were physically abused, 8.6 percent were sexually abused, 5.7 percent were psychologically maltreated, and 2.2 percent suffered medical neglect. Additionally, 7.1 percent experienced "other" maltreatment, which includes threatened abuse and parental substance-abuse [2]. One form of abuse does not make a child immune to another form of maltreatment. By evaluating the numbers, the sum of all of the averages exceeds $100 \%$ ! This is not a typo. The fact is that in some cases of child maltreatment, the child could suffer from multiple forms of abuse. A child that is sexually abused can be psychologically maltreated, and a child that is neglected can be physically abused as well. As noted earlier, neglect is the number one form of abuse. Dental neglect, as defined by the American Academy of Pediatric
Dentistry, is the "willful failure of parent or guardian to seek and follow through with treatment necessary to ensure a level of oral health essential for adequate function and freedom from pain and infection" [3].

It is important for the provider and their staff to differentiate between a caregiver's lack of knowledge or the awareness of the need for a child's dental care from those who have been previously advised, but failed to act, on recommendations about a child's dental care needs. It is also prudent to consider a family's ability to access the recommended dental care resources. The availability of dental care, combined with the decision by the caregiver to not seek recommended dental care for a child, warrants reporting of dental neglect to child protective services. Pediatric dentists and oral maxillofacial surgeons may be able to assist those providers caring for children with concern for dental abuse or neglect through education of dental conditions and/or resources. It is critical to consider manifestations of dental neglect in assessment of the oral cavity [4]. Neglect exists on a continuum, and multiple forms of dental neglect endure. These can include, but are not limited to, extensive caries, early childhood caries, dental abscesses, facial cellulitis or abscess arising from untreated dental abscess, gingivitis and periodontal disease, and other oral health problems.

Physical abuse is the type of abuse that the general public envisions when child maltreatment is discussed. The poor child with a black eye or broken arm seems to rise to the stew of thoughts. Child physical abuse should be considered as a possible etiology in children with any type to trauma to the body. In the backdrop of the dental office, injuries to and affecting the lips, gingiva, tongue, palate, and teeth should raise concern [5]. Injuries to the head, face, neck are common in children who are physically abused, and some studies have shown that nearly $50 \%$ of all physical abuse involves those regions [3-6]. Bruising of the face, particularly the cheeks, ears, and sides of the face, is concerning for abuse by location, in a child of any age $[7,8]$. Oral injury may also be an indication of physical abuse $[5,7]$. Non-accidental oral injuries are usually due to blunt force trauma, but penetrating injury inflicted with objects and thermal or chemical burns are 
also seen. Oral injury can be easily missed by the general medical practitioner, unless the examiner carefully inspects all aspects, structures of the peri-oral and intra-oral areas, as well as the pharynx $[3,4]$. Careful evaluation of the reported mechanism of injury and developmental assessment of the child can help in the determination of the plausibility of accidental injury as an explanation for the findings.

Bruising or lacerations of the lips are the most common abusive injuries to the mouth [5]. Mucosal lacerations, dental trauma, tongue injury, and gingival lesions can also serve as reminders of past physical abuse. Review of injury types observed in abused children showed 59\% with facial injuries, but only $11 \%$ had intra oral injuries recorded, even though facial injury involving cheeks, nose, or lips overlying the mouth is common [4]. Frequency distribution of mouth injuries: lips 54\%, oral mucosa $15 \%$, teeth $12 \%$, gingiva $12 \%$, and tongue $7 \%$ [4]. A brief word about sexual abuse should be acknowledged. Dentists should be observant for manifestations of sexually transmitted infections in the oral cavity. Also, palatial petechia has been documented in forced fellatio. However, negative findings in a sexual abuse examine does not rule out the fact that the act did not occur. History is of the utmost concern for this matter. If child sexual abuse/assault is a concern, the child should be reported to the child abuse hotline, and effort should be made for a forensic interview and exam.

\section{Reporting Child Abuse and Neglect}

Child Protective Services (CPS) relies on individuals and institutions reporting possible child abuse and neglect to accomplish this goal. Because anyone can report potential child maltreatment, there are many different types of sources from which CPS can receive a report. A report source is defined as the person who notified a CPS agency of the alleged child maltreatment and are grouped into the categories of professional, nonprofessional and unclassified. Professional report sources are sources that encounter the child as part of their occupation and account for nearly two-thirds of reports (65.7\%) and include medical professionals such as dentists. Nonprofessional report sources are individuals who do not a relationship with the child based on their occupation, such as neighbors, friends, or relatives. Unclassified includes anonymous and unknown [2]. Laws vary by state regarding reporting possible child abuse or neglect, but nearly every state has a law mandating certain professionals (medical, educational, law enforcement, etc.) and institutions (schools, hospitals, etc.) to inform a CPS agency of suspected child abuse and neglect [1]. Mandatory reporters are required to report the facts that led them to suspect child abuse but are not required to provide proof [9]. Reports can be made 24 hours-a-day, 7 daysa-week.

\section{References}

1. The CAPTA Reauthorization Act of 2010 (2010) 42 U.S.C. §5106a.

2. US department of Health \& Human Services, Administration for Children and Families, Administration on Children, Youth and Families, Children's Bureau (2019). Child maltreatment 2017.

3. Kellogg N (2005) American Academy of Pediatrics Committee on Child Abuse and Neglect. Oral and dental aspects of child abuse and neglect. Pediatrics 116(6): 1565-1568.

4. Naidoo S (2000) A profile of the oro-facial injuries in child physical abuse at a children's hospital. Child Abuse \& Neglect 24(4): 521-534.

5. Maguire S, Hunter B, Hunter L (2007) Diagnosing abuse: a systematic review of torn frenum and other intra-oral injuries. Archives of Diseases in Children 92(12): 1113-1117.

6. Christian CW, Mouden LD (2009) Maxillofacial, neck, and dental manifestations of child abuse. In: Reece RM, Christian CW, eds. Child Abuse Medical Diagnosis \& Management. $3^{\text {rd }}$ edition. American Academy of Pediatrics pp. 189-209.

7. Maguire S, Mann MK, Sibert J, Kemp A (2005) Are there patterns of bruising in childhood which are diagnostic of or suggestive of abuse? A systematic review. Arch Dis Child 90(2): 182-186.

8. Maguire S (2010) Which injuries may indicate child abuse? Arch Dis Child Educ Pract Ed 95(6):170-177.

9. (2014) Child Welfare Information Gateway. Mandatory reporters of child abuse and neglect. Department of Health and Human Services, Children's Bureau. Washington, DC: US.
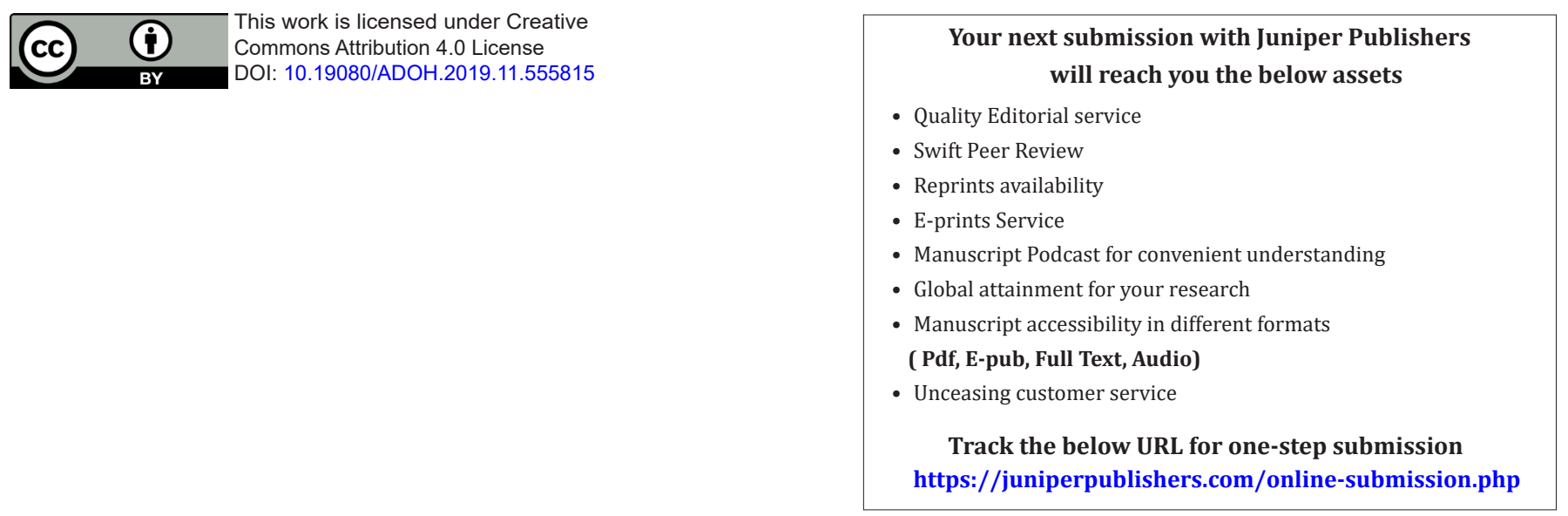